\title{
Implementação de um Sistema de Gestão Ambiental (SGA) no Hospital Municipal de Novo Hamburgo/RS.
}

\author{
Application of an Environmental Management System (EMS) at the Municipal \\ Hospital of Novo Hamburgo / RS.
}

\author{
Thiago Tepasse de Brum' (*) \\ Regina Célia Espinosa Modolo² \\ Carlos Alberto Mendes Moraes ${ }^{3}$
}

\section{Resumo}

O sistema de gestão ambiental inclui estrutura organizacional, atividades de planejamento, responsabilidades, práticas, procedimentos, processos e recursos para desenvolver, implementar, alcançar, rever e manter a política ambiental. Dessa forma, este estudo visou criar um modelo de Sistema de Gestão Ambiental (SGA) para o Hospital Municipal de Novo Hamburgo, considerado de médio porte. Foi proposta uma metodologia com cinco etapas: Etapa 1 - revisão bibliográfica; Etapa 2 - análise situacional - diagnóstico ambiental; Etapa 3 - coleta de dados; Etapa 4 - planejamento; Etapa 5 - Implementação do SGA. O diagnóstico ambiental realizado neste estudo demonstrou ser uma ferramenta eficaz na identificação de fatores de não conformidades da gestão ambiental, o que possibilitou a construção de uma proposta de modelo de sistema de gestão ambiental aplicável aos serviços de saúde. A implantação desse sistema de gestão ambiental no ambiente de saúde trouxe inúmeros benefícios como a redução de resíduos e efluentes líquidos, a preservação dos recursos naturais, o uso de materiais e insumos com menor impacto ambiental, a redução de custos, a preservação da saúde humana e do meio ambiente. Destaca-se, ainda, que o sucesso no desenvolvimento e manutenção de um SGA depende da importância atribuída pela alta administração, bem como de alguns fatores-chave, como as características ambientais e culturais de cada serviço e, principalmente, de seus colaboradores, os quais deverão estar devidamente motivados e envolvidos no processo.

Palavras-chave: Sistema de Gestão Ambiental; Sustentabilidade; Resíduos de Serviços de Saúde.

\section{Abstract}

The environmental management system includes organizational structure, planning activities, responsibilities, practices, procedures, processes and resources to develop, implement, achieve, review and maintain environmental policy. In this way, the proposal in developing this study aimed to create a model of Environmental Management

I Msc.; Gestão Ambiental; Universidade Federal de Ciências de Saúde de Porto Alegre, UFSCPA; Endereço: Rua Sarmento Leite, 245, Centro Histórico, CEP: 90050- I70, Porto Alegre-RS, Brasil; E-mail: thiagotepasseh@gmail.com (*) Autor para correspondências

2 Dra.; Agrônoma; Universidade do Vale do Rio dos Sinos, Unisinos, Centro de Ciências Exatas e Tecnológicas; Endereço: Avenida Unisinos, Cristo Rei, CEP: 93022-000, São Leopoldo-RS, Brasil; E-mail: reginaem@unisinos.br

3 Dr.; Engenheiro Metalúrgico; Universidade do Vale do Rio dos Sinos, Unisinos, Centro de Ciências Exatas e Tecnológicas; Endereço:Avenida Unisinos, Cristo Rei, CEP: 93022-000, São Leopoldo-RS, Brasil; E-mail: cmoraes@unisinos.br

Recebido para publicação em 06/06/2019 e aceito em II/II/2019

\begin{tabular}{lllllll}
\hline Ambiência & Guarapuava (PR) & v.l5 n.2 & P. $403-416$ & Maio/Ago 20I9 & ISSN I808 - 025I
\end{tabular}


System (EMS) for medium-sized hospital services. As a research strategy, we chose the case study, a methodology was proposed with five steps: Step 1 - bibliographic review; Step 2 - situational analysis; Step 3 - data collection; Step 4 - Planning; Step 5 - Implementation of the EMS. The environmental diagnosis carried out in this study proved to be an effective tool in the identification of nonconformity factors of environmental management, which made it possible to prepare a proposal for an environmental management system model applicable to health services. The implementation of the environmental management system in the health environment has brought numerous benefits such as the reduction of waste and liquid effluents, the preservation of natural resources, the use of more environmentally correct materials and inputs, cost reduction, preservation of human health and the environment. It is also important to note that success in the development and maintenance of an EMS depends on the importance given by top management, as well as on some key factors, such as the environmental and cultural characteristics of each service and, especially, its employees. which should be properly motivated and involved in the process.

Keywords: Environmental Management System; Sustainability; Waste from Health Services.

\section{Introdução}

As empresas têm a tendência de adotar diversos procedimentos que utilizam o meio ambiente para reforçar a sua competitividade. Se o meio ambiente era considerado, inicialmente, um custo assumido pelas empresas, hoje em dia, elas usam instrumentos que, ao mesmo tempo que protegem o meio ambiente, utilizam os recursos naturais de forma mais eficiente. Desse modo, uma das principais ferramentas utilizadas na política econômica das organizações tem sido a implementação de um SGA (LOZANO; VALLÉS, 2007).

Corroborando com os autores citados anteriormente, os estudos realizados por Chan e Hawkins (2010) indicam que a implantação de um SGA traz como benefícios o reforço da competitividade e do desempenho financeiro, além de ser capaz de afetar positivamente o envolvimento dos trabalhadores em sua implementação. Por outro lado, Silva (2008) constatou que os benefícios para a empresa com a implementação de um SGA (Sistema de Gestão Ambiental) são inúmeros e representam a melhoria da imagem da organização, o aumento da produtividade, a conquista do respeito dos funcionários, a facilidade de negociação e obtenção de financiamentos, entre outros.

Contribuindo com esse pensamento, Fisher et al. (2009) comentam que as empresas perceberam que a necessidade de proteger o ambiente significa analisar sua responsabilidade do ponto de vista ambiental, reconhecer as áreas problemáticas, documentar a situação atual, além de fazer todo o esforço no sentido de obter melhorias. Para isso, não basta considerar apenas os processos produtivos, mas toda a cadeia de processos da empresa. Nessa perspectiva, a relação entre organizações, sociedade e meio ambiente alteram as formas de gestão e a busca pelo desempenho, surgindo assim o desafio de inovar e preservar o meio ambiente simultaneamente (GONÇALVES-DIAS; GUIMARÃES; SANTOS, 2012).

Cabe destacar ainda que o sucesso de um SGA pode ser influenciado em função de como ele é implementado, assim como por condições internas e externas da empresa, ou seja, devese considerar que os ambientes em que os SGAs operam podem variar em termos de cultura 
corporativa, estilos de gestão, ambiente legislativo, metas da empresa, partes interessadas, entre outros fatores, incluindo, nomeadamente, o ambiente natural, o que tem acarretado a variedade de resultados encontrados (NAWROCKA; PARKER, 2009).

Além disso, ressalta-se que o apoio e o comprometimento da alta gerência são vitais para que se garanta uma ampla compreensão das questões ambientais e um comprometimento com elas, pois, só assim, a adoção de SGAs será facilitada. Dessa forma, é possível manter o sistema ao longo do tempo, a fim de reduzir os impactos ambientais (ZUTSHI; SOHAL, 2004).

A partir desse contexto, demanda-se uma gestão ambiental inovadora, eficiente e estratégica, que integre, aos processos produtivos, ações ambientais para prevenir, controlar e poluir menos o meio ambiente (JABBOUR, 2014). Para Maçaneiro (2012), as questões ambientais devem ser vistas como propulsoras de inovações e possibilidades de desenvolvimento tecnológico, econômico e competitivo. É nesse cenário que as inovações sustentáveis podem contribuir significativamente com a gestão ambiental das organizações.

Para To e Tang (2014), os três principais fatores motivadores para adoção do SGA são a conscientização ambiental dos colaboradores, que pode reduzir o consumo de matérias-primas e a poluição; a conformidade com a regulamentação ambiental; e a melhoria da eficiência que pode incluir a eficiência administrativa e ambiental. A implantação de um SGA normalmente segue a metodologia PDCA (Plan - Do - Check - Act) (ABNT, 2004). De acordo com Neves e Rozemberg (2010, p. 163-164), essa metodologia é um processo evolutivo que, ao passar por cada uma das etapas, promove uma análise completa das estratégias e métodos traçados para as questões ambientais, buscando a melhoria contínua do sistema. Dessa forma, este estudo visou propor um Sistema de Gestão Ambiental (SGA) por meio da análise de aspectos e impactos ambientais para Unidades de Saúde.

\section{Metodologia}

A pesquisa aplicada neste estudo foi do tipo exploratório-descritiva. $\mathrm{O}$ estudo foi realizado no Hospital Municipal de Novo Hamburgo no Estado do Rio Grande do Sul.

Como estratégia de pesquisa, escolheu-se o estudo de caso de um processo. $\mathrm{O}$ estudo de caso é utilizado para conhecer fenômenos organizacionais, sociais, grupais, políticos entre outros (YIN, 2005). Assim, para esta pesquisa, o estudo de caso pode ser utilizado, justamente, por analisar um fenômeno organizacional que envolve diversos aspectos ambientais, sociais e econômicos através de cinco etapas que podem ser evidenciadas na Figura 1.

Etapa 1: Foi realizada uma pesquisa bibliográfica para a elaboração deste estudo, pesquisa que pode ser observada nas primeiras páginas deste artigo.

Etapa 2: Realização da pesquisa documental. No hospital onde foi executada a pesquisa, foram analisados documentos como a licença ambiental, política, metas e objetivos, de uma forma geral, também listas de treinamentos realizados com os colaboradores e manuais. $\mathrm{O}$ atendimento aos requisitos ambientais legais foram analisados, assim como os aspectos de determinação de metas e objetivos; implementação e operação por meio da disponibilização de recursos, investimentos, comunicação, treinamento e conscientização ambiental; documentação e controle; preparação e respostas a emergências; verificação e monitoramento; ação corretiva e preventiva; controle de registros; análise pela administração. Em relação à pesquisa documental, 


\section{Figura 1 - Fluxograma das etapas de implantação do Sistema de Gestão Ambiental (SGA).}

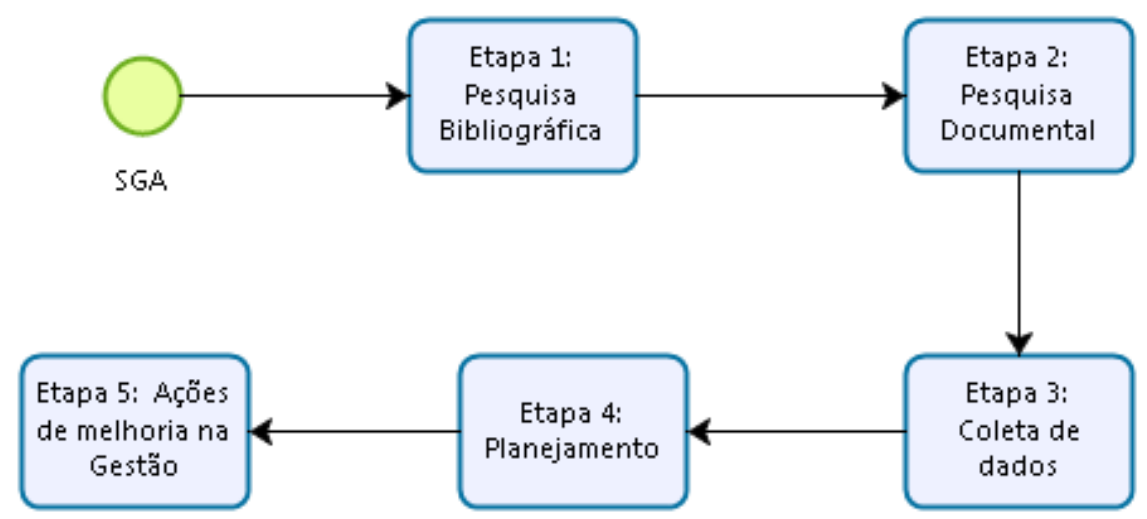

Fonte: $O$ autor.

segundo Creswell (2010), ela auxilia como fonte de evidências escritas e informações relevantes ao estudo. Para Bardin (2004), a análise documental é uma fase preliminar da constituição de um serviço de documentação ou de uma base de dados.

Etapa 3: Coleta de dados. Como técnicas de coleta de dados, utilizou-se a análise documental. As constatações servem para disponibilizar informações adicionais sobre o que está sendo analisado, servindo como fonte complementar para o levantamento de evidências do estudo de caso (YIN, 2010). No caso desta pesquisa, a observação foi realizada de maneira direta, uma vez que o pesquisador esteve inserido no campo investigado, participou de reuniões do comitê de Resíduos de Serviços de Saúde (RSS), análise de documentos internos e acompanhou os processos.

As observações e controles ocorreram de 1 a 15 de maio de 2018, para ser possível uma base de comparação. $\mathrm{O}$ envolvimento nessas atividades serviu como fonte de informações para saber quais processos foram desenvolvidos para a correta implementação do SGA, por meio de registros em planilhas da sequência de operações executadas, análise da documentação existente (dados de aquisição de materiais, registros de insumos e destinação de resíduos) e documentação fotográfica. Essa análise gerou fluxogramas do processo, para identificar oportunidades de melhorias, bem como auxiliou na elaboração do modelo de gestão ambiental proposto para os serviços hospitalares.

Etapa 4: Planejamento. O Planejamento ocorreu através de cinco iniciativas:

a) Implementar práticas voltadas à melhoria contínua de seus processos, visando à prevenção e redução da poluição e dos impactos ambientais, associados ao ar, água, solo, recursos naturais, entre outros. A empresa deve estabelecer e manter procedimentos para identificar os aspectos ambientais de suas atividades, produtos e serviços, e que estes possam ser por ela controlados, a fim de determinar aqueles que tenham ou possam ter impactos significativos sobre o meio ambiente. A identificação dos aspectos ambientais e da análise dos impactos associados é de grande importância para toda a organização, devido à grande oportunidade de envolvimento de todos os setores com a implementação do SGA. A empresa deve ainda assegurar que os aspectos relacionados aos impactos significativos sejam considerados na definição de seus objetivos ambientais;

b) Beneficiar as partes interessadas (pacientes, colaboradores, fornecedores, órgãos governamentais e comunidades), por meio de suas práticas ambientais estabelecidas. Para a 
avaliação dos aspectos e impactos, utilizou-se o modelo proposto por Seiffert (2007), com dados da atividade e operação da empresa, caracterização, verificação, avaliação da significância, controles já existentes, legislação regulamentadora pertinente; permitindo assim, a avaliação da importância dos aspectos e impactos ambientais. O objetivo foi definir uma hierarquia dos aspectos e impactos, possibilitando a priorização de medidas preventivas e corretivas;

c) Estimular práticas de sustentabilidade ambiental, de forma dinâmica e evolutiva, por meio de programas de educação ambiental. Para a empresa, foram definidos três objetivos, cuja responsabilidade cabe aos setores gerenciais e operacionais e são apoiados pela direção da empresa: Redução de geração de resíduos sólidos, por meio do controle dos processos internos e através da redução do volume de papel descartado no setor administrativo. O segundo objetivo é realizado com foco na redução do consumo de recursos naturais, consumo de energia elétrica $\mathrm{kWh} / \mathrm{mês}$ e consumo de água tratada;

d) Monitorar o desempenho do SGA pelo estabelecimento de objetivos e metas e acompanhamento permanente de seu cumprimento, por meio de Programas de Gestão. No controle dos impactos significativos, atualmente é realizado um monitoramento da utilização de energia elétrica, pois, além da relevância ambiental, ela é um dos custos de produção relevantes. Em relação aos resíduos sólidos do processo assistencial, existe um controle operacional, em que tooas os RSS são encaminhados a uma empresa especializada no tratamento desses resíduos;

e) Atender a legislação aplicável e outros requisitos subscritos, que se relacionem com seus aspectos ambientais. A organização deve estabelecer, implementar e manter procedimento para identificar, ter acesso à legislação aplicável e a outros requisitos por ela subscritos aplicáveis aos aspectos ambientais de suas atividades, produtos e serviços. $\mathrm{O}$ atendimento a esse requisito apoia o compromisso político da empresa com a conformidade legal e é indispensável ao SGA. Dessa forma, a empresa deverá identificar e ter acesso aos requisitos legais vigentes relativos ao meio ambiente.

Etapa 5: Durante o desenvolvimento e avaliação do sistema, foram realizadas várias ações de melhoria na gestão, algumas já com resultados e outras em fase de monitoramento, constituindo-se, assim, em uma implementação progressiva de médio (acima de um ano) e longo (acima de três anos) ou de curto (menos de um ano) e médio prazo. Para essa etapa, deverá ser definido o escopo para a implementação, ou seja, as condições e limites do SGA. A empresa tem liberdade para definir esses limites, podendo fazê-los para toda ou parte dela. Neste estudo, levando-se em conta o escopo já definido nas etapas anteriores, considerou-se conveniente a abrangência de toda a empresa.

\section{Resultados e Discussão}

O Hospital Geral é uma unidade de saúde gerenciada pela Fundação de Saúde Pública de Novo Hamburgo (FSNH), uma instituição pública de direito privado, vinculada à Prefeitura Municipal através da Secretaria Municipal de Saúde, considerada de porte médio. O Hospital, atualmente, tem 230 (duzentos e trinta) leitos, realizando uma média mensal de 1.000 internações hospitalares. Presta atendimento ininterrupto em urgência e emergência, na sua totalidade pelo Sistema Único de Saúde (SUS).

Em relação às contribuições dos treinamentos de conscientização, foi possível verificar que os colaboradores entenderam como um processo fundamental para disseminar e esclarecer dúvidas em relação ao SGA e os impactos que as atividades de cada um podem ocasionar ao meio ambiente. Os Entrevistados ressaltaram que as principais contribuições são o consumo consciente, economia, melhor aproveitamento dos recursos, reciclagem e redução na geração de 
resíduos. Nessa perspectiva, entende-se que a mudança de comportamento é consequência do processo de conscientização. (CROTTI; MAÇANEIRO, 2017).

Para Khanna, Laroyia e Sharma, (2009), a descrição de um caso prático é importante, pois contribui com novos argumentos e reforça os existentes. Além disso, mesmo já existindo casos de integração de sistemas de gestão (GRAEL; OLIVEIRA,2010; CHAIB, 2005), a apresentação de um estudo de caso de um hospital pode contribuir tanto para o setor de saúde quanto para a academia.

A empresa deve assegurar que os recursos administrativos (financeiros e equipamentos) e humanos (treinamento) sejam adequadamente controlados e incorporados ao planejamento. Além disso, para atingir os objetivos propostos, a empresa deve designar as responsabilidades, definir o cronograma, determinar os locais e o método adotado para atingir cada objetivo. (BRENDLER, 2011).

Outro benefício diz respeito ao aspecto mercadológico, pois, com a implementação de um Sistema de Gestão Ambiental, as possibilidades de incremento nas relações comerciais com novos clientes, locais ou regionais, aumentam consideravelmente. Aliado ao desenvolvimento comercial, há também o efeito do marketing positivo, decorrente da "venda" da imagem de uma empresa preocupada com as questões de meio ambiente, saúde e segurança do trabalho. Em um ambiente de extrema competitividade empresarial, a implementação do SGA em organizações da área da saúde pode servir para reafirmar, perante as partes interessadas - pacientes, órgãos fiscalizadores e comunidade - a preocupação que têm com esses assuntos, conferindo-lhes credibilidade.

Para análise dos processos, utilizou-se o método observacional que auxiliou no diagnóstico da gestão ambiental nos serviços de saúde. Foi realizada a observação dos procedimentos, das técnicas de manejo e comportamentos desenvolvidos nessa instituição, relacionadas à prevenção e/ ou conservação ambiental. A avaliação documental dos procedimentos adotados pela organização constou da análise das normas e rotinas dos serviços, assim como o fluxograma das atividades apresentado na Figura 2, o qual identificou oportunidades de melhorias.

\section{Figura 2 - Fluxograma de entradas e saídas.}

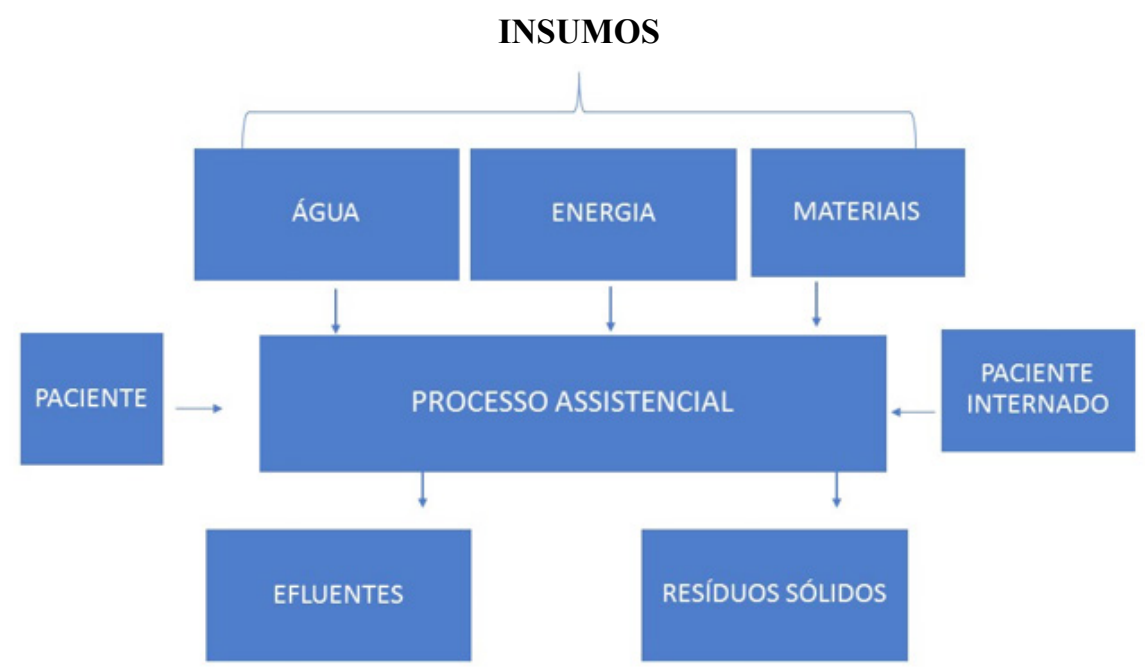

Fonte: $O$ autor.

$\mathrm{Na}$ Figura 3 está representado o modelo de SGA proposto e que está sendo implementado nos serviços assistenciais do hospital. O modelo se divide em quatro etapas, que serão descritas 
a seguir. Contribuindo com os resultados alcançados, Domingues (2017) teve em seu trabalho resultados similares com implementação de Procedimentos Operacionais Padrão (POP), em seu objetivo de servir de instrumento de gestão auxiliar. Assim como o SGA, os procedimentos contribuíram para a qualidade no processo de gerenciamento para reduzir a descontinuidade de práticas advindas da rotatividade de funcionários e a minimização dos riscos ocupacionais, melhorando a saúde e a segurança do trabalhador.

Figura 3 - Fluxograma proposto do SGA em serviços de saúde.

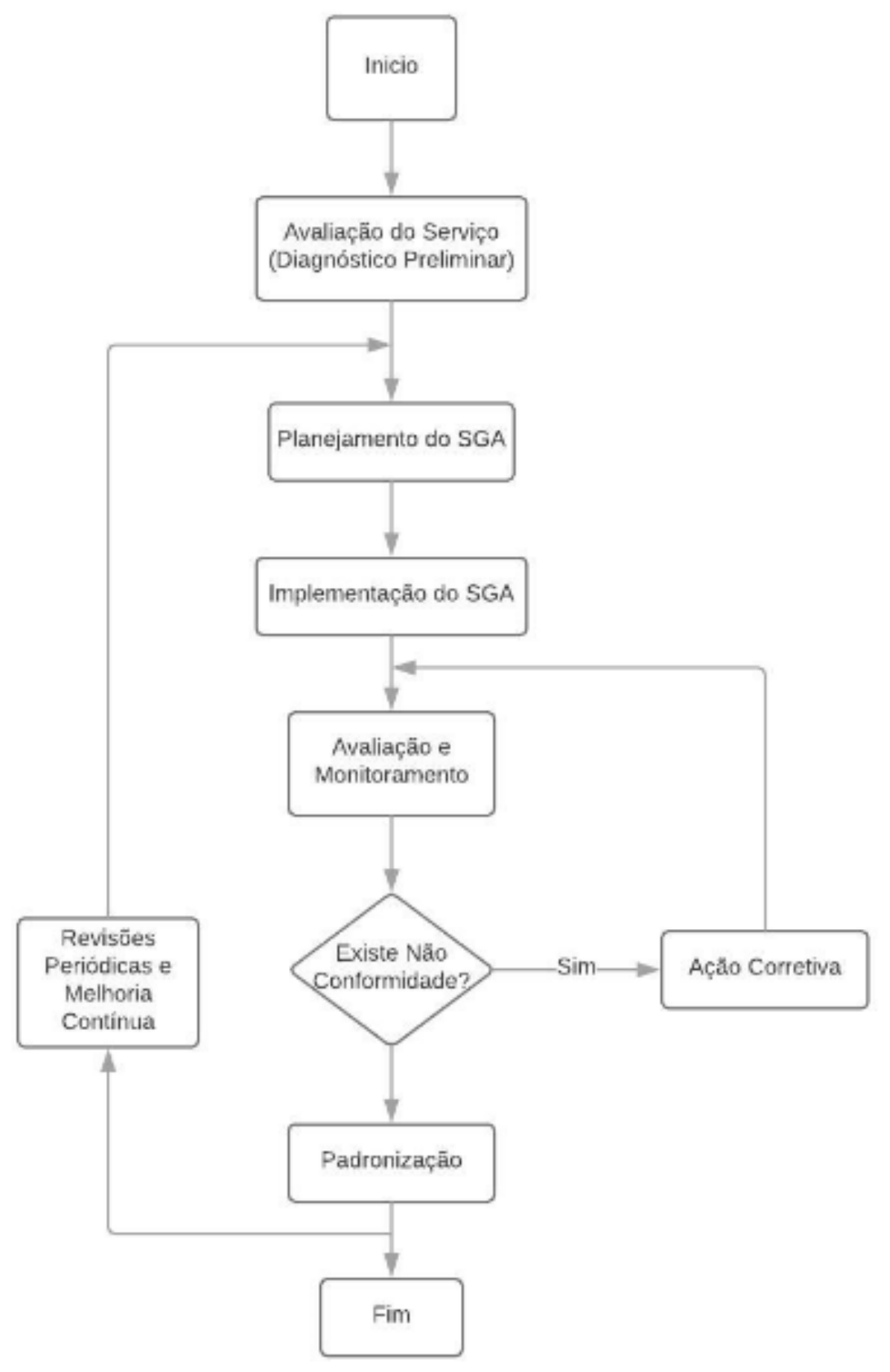

Fonte: $O$ autor.

1a Etapa: Avaliação do serviço: Diagnóstico preliminar, a fim de se obter sucesso na implementação de um SGA. É necessária a realização de um diagnóstico preliminar, identificando o estágio de conscientização ambiental que o serviço possui, bem como as possíveis dificuldades a serem superadas. Existem diversas ferramentas as quais podem ser utilizadas para identificar 
as prováveis dificuldades que serão enfrentadas como: levantamento das ações já realizadas, pontuando os possíveis motivos do sucesso ou fracasso; o estudo do clima organizacional e o histórico ambiental da empresa.

2a Etapa: Planejamento do sistema de gestão ambiental: a partir da identificação dos aspectos ambientais resultantes das atividades realizadas no serviço, deverão ser selecionadas as que causarem impactos mais relevantes e significativos. Cabe à empresa escolher a ferramenta pertinente entre as diversas existentes na literatura. Para a realização de controle, análises e modificações, recomenda-se que a empresa tenha uma sistemática interna de controle e avaliação conforme a legislação. É indispensável o conhecimento dos aspectos ambientais relacionados às atividades, produtos e serviços da organização para realizar uma análise eficaz da sua aplicabilidade. Os objetivos e metas devem ser estabelecidos a partir da priorização dos aspectos e impactos ambientais significativos da empresa, identificados no pré-diagnóstico.

3a Etapa: Implementação do sistema de gestão ambiental: a implementação bem-sucedida de um SGA exige o comprometimento de todos os funcionários da organização. Este começa nos níveis gerenciais mais elevados da empresa, em que a alta administração estabelece a política ambiental e assegura que esse sistema seja implementado. Como parte desse comprometimento, a gerência designa seu representante específico, com responsabilidade e autoridade definidas para a implementação do SGA. Também estabelece e mantém recursos para a identificação das necessidades de treinamento. $\mathrm{O}$ serviço formaliza procedimentos para a comunicação, recebimento e documentação das informações pertinentes, a fim de atender às solicitações das partes interessadas, inclusive sobre impactos ambientais associados às operações da organização. Para que a comunicação seja eficaz nos diferentes níveis hierárquicos dos serviços, recomenda-se a utilização de uma planilha de controle, evitando as possíveis falhas de comunicação. Com o intuito de assegurar o controle e o sucesso na implantação do SGA, é fundamental a elaboração da documentação para toda a equipe. Segundo a norma, a documentação deve conter uma descrição dos elementos centrais do sistema e apresentar com clareza as diversas interações entre eles. Recomenda-se a elaboração do Manual de Gestão Ambiental com Procedimento Operacional Padrão que, além do procedimento técnico, contenha ações corretivas, rotinas operacionais, instruções de trabalho, planilhas e formulários.

4a Etapa: Avaliação e monitoramento do SGA.: faz-se necessária a realização de medições e monitoramentos sistemáticos do sistema implementado na organização, para assegurar uma melhoria contínua do desempenho ambiental. É importante salientar que os resultados dessas atividades devem ser utilizados, não somente para avaliar se os objetivos e metas foram atingidos, mas também para ajudar a identificar onde as correções ou melhorias são prioritárias.

A seguir são apresentadas algumas oportunidades de melhoria que foram implementadas:

a) Atualização e implantação do PGRSS (Plano de Gerenciamento de Resíduos de Serviços de Saúde), pois, o plano existente necessitava de alguns ajustes em relação a RDC no 222 (ANVISA, 2018) e precisava ser aplicado. Foi realizada capacitação nos quatro turnos de trabalho (manhã, tarde, noite I e noite II) e em todos os setores assistenciais, durante quatro dias in loco, totalizando 283 profissionais sensibilizando os técnicos de enfermagem (210), enfermeiros (30) e higienizadores (43) sobre a importância da segregação e a responsabilidade de cada profissional com o processo, demonstrando os tipos de resíduos, características, responsabilidades e consequências de seu descarte incorreto;

b) Foi removido o porta-copos de plásticos do lado dos bebedouros e realizada uma campanha de conscientização sobre a importância da redução do consumo de plástico e a sensibilização do uso de garrafinhas e xícaras individuais; 
c) Eram utilizadas duas embalagens para a esterilização dos materiais oriundos do laboratório, pois o plástico que envolvia os resíduos não resistia à temperatura de $121^{\circ} \mathrm{C}$ da autoclave. Segundo a Resolução RDC no 222 (ANVISA, 2018), as culturas e os estoques de microrganismos; os resíduos de fabricação de produtos biológicos, exceto os de medicamentos hemoderivados; os meios de cultura e os instrumentais utilizados para transferência, inoculação ou mistura de culturas; e os resíduos de laboratórios de manipulação genética devem ser tratados. Devem ser submetidos a tratamento, utilizando processos que vierem a ser validados para a obtenção de redução ou eliminação da carga microbiana. Iniciou-se a utilização de um plástico de maior resistência para ser usado na autoclave;

d) Mudança da rotina de impressão dos exames laboratoriais. Com a utilização dos computadores, os exames são encaminhados pelo laboratório interno através do sistema integrado; a equipe de enfermagem e os médicos imprimem apenas se o paciente estiver em transferência externa para outro hospital. Quando a transferência for interna, apenas troca de setor, quarto e/ ou leito e os exames ficam apenas em formato digital;

e) Mudança da rotina de impressão da conferência do ponto do $\mathrm{Rh}$, pois eram impressos todos os espelhos pontos dos funcionários para ser realizada a conferência dos mais de dois mil colaboradores. Essa conferência passou a ocorrer no computador com a parametrização do sistema de Gestão de Pessoas interno e o próprio software que aponta as irregularidades dos pontos;

f) Mudança da rotina de encaminhamento do contracheque por e-mail, pois eles eram impressos com o espelho ponto dos funcionários que o assinavam e retiravam seu contracheque. Com a mudança os contracheques passaram a ser enviados por e-mail para os colaboradores através do próprio sistema interno e os espelhos ponto passaram a ser entregues impressos apenas quando solicitados;

g) Substituição do papel toalha por um de melhor qualidade, pois o papel toalha de melhor qualidade possui maior taxa de absorção e, apesar de ter custo maior, vai reduzir a quantidade de folhas para a secagem das mãos. Serão confeccionados materiais de divulgação para serem colocados nos banheiros a fim de sensibilizar os usuários de que são necessárias apenas duas folhas para secar as mãos;

h) Venda de materiais recicláveis, pois, com a revisão, atualização e implantação do PGRSS (Plano de Gerenciamento de Resíduos de Serviços de Saúde), os resíduos recicláveis podem ser vendidos para cooperativas, com a correta segregação do vidro - oriundo do Serviço de Nutrição e Dietética - que é armazenado em carrinhos com identificação para facilitar o transporte interno; do papelão que resulta dos processos da farmácia e almoxarifado principalmente, com recolhimento duas vezes por dia para evitar a inutilização de algum espaço pela quantidade do volume gerado; do papel branco que sai das áreas administrativas, com significativa quantidade, dos setores de Recursos Humanos, Faturamento e Contabilidade. Nas recepções e nos postos de enfermagem foram colocadas caixas para a segregação do papel branco, que é recolhido uma vez por semana ou quando for solicitado; e plástico, oriundo de todos os setores do hospital com recipientes identificados, contendo sacos vermelhos conforme a Resolução no 358 (CONAMA, 2005). A eficiência dessa etapa está intimamente relacionada à educação continuada na forma de treinamentos, fiscalizações e reuniões, fortalecendo a conscientização dos funcionários para importância de segregarem os resíduos corretamente, em função da segurança, saúde e economia dos próprios colaboradores, pacientes, familiares e fornecedores.

No Quadro 1 estão representadas algumas ações de melhoria implantadas, obtendo resultados comparativos nos meses de maio e junho de 2018. 


\section{Quadro 1 - Resultados das ações de melhoria implantadas nos serviços hospitalares no primeiro semestre de 2018.}

\begin{tabular}{|c|c|c|c|c|}
\hline Ação Implantada & $\begin{array}{l}\text { Redução de } \\
\text { Resíduos }\end{array}$ & $\begin{array}{l}\text { Redução de } \\
\text { efluentes }\end{array}$ & $\begin{array}{l}\text { Redução de } \\
\text { custo/mês }\end{array}$ & $\begin{array}{c}\text { Redução de custo/ } \\
\text { ano }\end{array}$ \\
\hline $\begin{array}{l}\text { Atualização e implantação do } \\
\text { PGRSS (Plano de Gerenciamento } \\
\text { de Resíduos de Serviços de Saúde). }\end{array}$ & $22,9 \%$ do total & & $\mathrm{R} \$ 5954,00$ & $\mathrm{R} \$ 71448,00$ \\
\hline $\begin{array}{c}\text { Mudança da rotina do uso de copo } \\
\text { descartável. }\end{array}$ & $\begin{array}{l}5000 \text { copos } \\
\text { descarte/mês }\end{array}$ & & $\mathrm{R} \$ 102,00$ & $\mathrm{R} \$ 1124,00$ \\
\hline $\begin{array}{l}\text { Mudança da rotina na embalagem de } \\
\text { materiais para esterilização. }\end{array}$ & Sim & & $\mathrm{R} \$ 167,28$ & $\mathrm{R} \$ 2007,36$ \\
\hline $\begin{array}{c}\text { Mudança da rotina da desinfecção } \\
\text { das máquinas de hemodiálise com } \\
\text { hipoclorito de sódio. }\end{array}$ & & $\begin{array}{l}936 \text { litros/ano } \\
\text { Hipoclorito de } \\
\text { Sódio } 5 \%\end{array}$ & $\mathrm{R} \$ 107,45$ & $\mathrm{R} \$ 1289,40$ \\
\hline $\begin{array}{l}\text { Mudança da rotina de impressão dos } \\
\text { exames laboratoriais. }\end{array}$ & $\begin{array}{l}420 \text { folhas de } \\
\text { ofício/mês }\end{array}$ & & $\mathrm{R} \$ 26,85$ & $\mathrm{R} \$ 322,20$ \\
\hline $\begin{array}{l}\text { Mudança da rotina de impressão da } \\
\text { conferência do ponto do Rh. }\end{array}$ & $\begin{array}{l}280 \text { folhas de } \\
\text { ofício/mês }\end{array}$ & & $\mathrm{R} \$ 17,90$ & $\mathrm{R} \$ 214,80$ \\
\hline $\begin{array}{l}\text { Mudança da rotina de } \\
\text { encaminhamento do contracheque por } \\
\text { e-mail. }\end{array}$ & $\begin{array}{l}2067 \text { folhas de } \\
\text { ofício/mês }\end{array}$ & & $\mathrm{R} \$ 132,14$ & $\mathrm{R} \$ 1585,68$ \\
\hline $\begin{array}{l}\text { Substituição do papel toalha, por um } \\
\text { de melhor qualidade. }\end{array}$ & & & $\begin{array}{l}\text { Em fase de } \\
\text { medição }\end{array}$ & $\begin{array}{l}\text { Em fase de } \\
\text { medição }\end{array}$ \\
\hline Venda de materiais recicláveis. & $\begin{array}{l}733 \mathrm{~kg} / \mathrm{mês} \\
\text { de resíduos } \\
\text { vendidos }\end{array}$ & & $\mathrm{R} \$ 93,75$ & $\mathrm{R} \$ 1125,00$ \\
\hline Total & & & $\mathrm{R} \$ 6601,37$ & $\mathrm{R} \$ 79216,44$ \\
\hline
\end{tabular}

Fonte: O autor.

A análise crítica é realizada pela alta administração e mostra-se relevante para que o processo de melhoria contínua do sistema seja assegurado em nível estratégico e operacional. Os resultados obtidos na auditoria forneceram subsídios para realizar essa análise crítica, indispensável a uma avaliação permanente da política estabelecida, possibilitando correções de rumo e/ou padronização, bem como estabelecer novos objetivos e metas, buscando melhorar e aperfeiçoar o sistema. Com a implantação do modelo de SGA proposto neste estudo, foi possível perceber inúmeros benefícios tais como, a redução da geração de resíduos e efluentes líquidos. Outros aspectos relevantes que devem ser mencionados, estão diretamente relacionados à redução do consumo de água e energia devido à implementação do SGA, o que corrobora com a mitigação de impactos ambientais, como o uso de recursos naturais não renováveis.

Com a implantação do SGA, algumas ações de melhoria ainda estão em fase de monitoramento. As vantagens de praticar a segregação na origem são: redução dos riscos para a saúde e o ambiente, impedindo que os resíduos potencialmente infectantes ou especiais, que geralmente são frações pequenas, contaminem os outros resíduos gerados no hospital; diminuição de gastos, já que apenas terá tratamento especial uma fração e não todos os resíduos; aumento da eficácia da reciclagem. 
Os resultados dessa pesquisa mostraram que, mudanças e inovações, as quais reduzem o impacto ambiental e os custos, melhoram a qualidade e a competitividade dos serviços. Nesse sentido, pode-se afirmar que as inovações permitem que as empresas usem mais produtivamente, uma série de insumos, de matéria-prima e fontes de energia, de forma a compensar os gastos feitos para preservar mais o meio ambiente, tornando-as assim, mais competitivas.

As organizações devem adotar novos princípios e ferramentas para a produção de bens e serviços com foco na sustentabilidade. O surgimento de novos princípios e ferramentas impulsionam a evolução da estratégia da manufatura, e consequentemente a incentivam as mudanças incrementais no sistema produtivo. Os processos industriais são caracterizados por entradas (matérias-primas, energia e mão de obra) e saídas (produtos, serviços, emissões para o ar e água e resíduos). As emissões e os resíduos gerados podem ser controlados e reduzidos por mudanças realizadas no sistema produtivo, e que venham ao encontro de novos princípios como o de produção mais limpa, que visam principalmente à redução do uso de matérias-primas não renováveis e tóxicas na fonte (KIPERSTOK et al., 2013).

\section{Conclusão}

O diagnóstico ambiental realizado neste estudo demonstrou ser uma ferramenta eficaz na identificação de fatores de não conformidades da gestão ambiental, o que possibilitou a confecção de uma proposta de Sistema de gestão ambiental no Hospital Municipal de Novo Hamburgo, aplicável a outras unidades de saúde.

A implementação do sistema de gestão ambiental no Hospital Municipal de Novo Hamburgo trouxe inúmeros benefícios como a redução de resíduos e efluentes líquidos, a preservação dos recursos naturais, o uso de materiais e insumos ambientalmente corretos, a redução de custos, a preservação da saúde humana e do meio ambiente. Destaca-se, ainda, que o sucesso no desenvolvimento e manutenção de um SGA depende da importância atribuída pela alta administração, bem como de alguns fatores-chave, como as características ambientais e culturais de cada serviço e, principalmente, de seus colaboradores, os quais deverão estar devidamente motivados e envolvidos no processo, premissa esta que foi atendida no presente estudo.

O principal resultado foi alcançado por meio da ação de atualização e implantação do PGRSS (Plano de Gerenciamento de Resíduos de Serviços de Saúde), pois obteve 22,9\% de redução do total de resíduos gerados e segregados como infectante (biológico), que eram destinados à incineração e agora são encaminhados para aterro sanitário, proporcionando redução de $\mathrm{R} \$$ 71448,00 por ano. Uma ação importante de ser destacada pela facilidade de implementação e resultado imediato é a mudança da rotina do uso de copo descartável; com a divulgação e orientação sobre o uso desnecessário de copos descartáveis para ingerir água e café, obteve-se uma redução de 5000 copos descarte/mês, contribuindo para uma redução anual de $\mathrm{R} \$ 1124,00$.

Outro aspecto a se considerar no SGA são os elementos de uma cadeia de produção, pois, desde a industrialização de insumos e processamento de produtos até o transporte, recebimento e armazenamento, afetam diretamente o meio ambiente. Com a avaliação dos aspectos e impactos ambientais da empresa, foi possível verificar essa consideração, em que os aspectos são provenientes desde a matéria-prima até a geração de resíduos, provenientes do processo assistencial que, neste caso, avalia-se como significativo os RSS. Nessa gama de aspectos e impactos que atingem ao meio ambiente, constatou-se a importância de avaliá-los de acordo com a sua significância, visto que as suas consequências, frequências e probabilidade de acontecimentos alteram o seu grau de real impacto sobre o meio ambiente, pois apenas alguns que são de real significância devem ser controlados. 


\section{Referências}

ASSOCIAÇÃO BRASILEIRA DE NORMAS TÉCNICAS - ABNT. NBR ISO 14001:2004. Sistema de gestão ambiental: requisitos com orientações para uso. Rio de Janeiro: ABNT, 2004.

BARDIN, L. Análise de conteúdo. 3 ed. Lisboa: Edições 70, 2004.

BERTOLINO,M.T.; FRANK, B. Estudo da complementariedade de sistemas de gestão ambiental e sistemas de gestão da análise de perigos e pontos críticos de controle. Revista Eletrônica de Administração, REAd, Porto Alegre, v. 12, n. 3, mai./jun. 2006.

BRASIL. MINISTÉRIO DA SAÚDE. Agência Nacional de Vigilância Sanitária. Resolução RDC no 306 de 07 de dezembro de 2004. Dispõe sobre o regulamento técnico para o gerenciamento de resíduos de serviços de saúde. Diário Oficial da União. Brasília (DF). Senado; 2004.

BRENDLER, ELOI; LONDERO, LUCIANA. Integração do sistema de gestão ambiental no sistema de gestão de qualidade em uma indústria de confecções. Gest.Prod., São Carlos, v. 18, n. 1, p. 27-40, 2011.

BRITISH STANDARDS INSTITUTION. OHSAS 18001: occupational health and safety assessment series. London, 2007.

CAMPOS, L. M. S.; MELO, D. A. Indicadores de desempenho dos Sistemas de Gestão Ambiental (SGA): uma pesquisa teórica. Produção, v. 18, n. 3, p. 540-555, 2008.

CAMPOS, L. M. S.; MELO, D. A; MEURER, S. A. A importância dos indicadores de desempenho ambiental nos sistemas de gestão ambiental (SGA). In: ENCONTRO NACIONAL SOBRE GESTÃO EMPRESARIAL E MEIO AMBIENTE ENGEMA, 9., 2007, Curitiba. Anais... Curitiba: ABEPRO, 2007.

CASTILHO A, PIRES AR, GUERREIRO FJF, ALVES P, MARTINS C, GONÇALO D. Guia interpretativo NP EN ISO 14001: 1999. Apcer; 2001.

CHAIB, E. B. D’A. Proposta para implementação de sistema de gestão integrada de meio ambiente, saúde e segurança do trabalho em empresas de pequeno e médio porte: um estudo de caso da indústria Metalmecânica. Dissertação (Mestrado)-COPPE/ UFRJ, Rio de Janeiro, 2005.

CHAN, E. S.W.; HAWKINS, R. (2010). Attitude towards EMSs in an international hotel: an exploratory case study. International Journal of Hospitality Management, 29, 641-651.

CRESWELL, J. W. Projeto de pesquisa: métodos qualitativo, quantitativo e misto. 3.ed. Porto Alegre: Artmed/Bookman, 2010. 
CROTTI, KATIANE; MAÇANEIRO, MARLETE BEATRIZ. IMPLANTAÇÃO DA ISO 14001:2004: ESTUDO DE CASO DE UMA INDÚSTRIADE PAPEL DA REGIÃO CENTRO-SUL DO PARANÁ. REAd | Porto Alegre - Edição 86 - No 2- Maio / Agosto 2017 - p. $274-305$.

DOMINGUES, N.P.S. Gerenciamento dos resíduos de serviços de saúde instituição de ensino e pesquisa em saúde: estudo de caso na Faculdade de Saúde Pública - USP, 2017. 126 f. Dissertação em Ambiente, saúde e Sustentabilidade, Faculdade de Saúde Pública, Universidade de São Paulo, 2017.

FISHER, G. et al. Gestão da qualidade: segurança do trabalho e gestão ambiental. Tradução Ingeborg Sell. 2. ed. São Paulo: Blucher, 2009. 240 p.

GONÇALVES TRAVAGLINI R, MENDES V. Gerenciamento dos resíduos de serviços de saúde. São Paulo: Sana Domus; 2004.

GONÇALVES-DIAS, S. L. F.; GUIMARÃES, L. F.; SANTOS, M. C. L. Inovação no desenvolvimento de produtos "verdes": integrando competências ao longo da cadeia produtiva. Revista de Administração e Inovação, RAI, São Paulo, v. 9, n. 3, p. 129-153, jul./set. 2012.

GRAEL, P. F. F.; OLIVEIRA, O. J. Sistemas certificáveis de gestão ambiental e da qualidade: práticas para integração em empresas do setor moveleiro. Produção, v. 20, n. 1, p. 30-41, 2010.

JABBOUR, A. B. L. S. Evidências da relação entre a evolução da gestão ambiental e a adoção de práticas de green supply chain management no setor eletroeletrônico brasileiro. Revista de Administração, São Paulo, v. 49, n. 3, p. 606-616, jul./set. 2014.

KHANNA, H.; LAROYIA, S. C.; SHARMA, D. D. A Survey on Indian Experience on Integrated Management Standards (IMS). International Journal for Quality Research, v. 3, n. 3, 2009.

LOZANO, M.; VALLÉS, J. An analysis of the implementation of an environmental management system in a local public administration. Journal of Environmental Management, v. 82, n. 4, p. 495-511, 2007. PMid:16632169.

MAÇANEIRO, M. B.; CUNHA, S. K. Ecoinovação: um quadro de referência para pesquisas futuras. Revista Innovare, Ponta Grossa, PR, v.13, n. 1, p.266-289, jan./jul. 2012.

MAZZA, C.; ISIDRO- FILHO, A.; HOFFMANN, V. E. Capacidades dinâmicas e inovação em serviços envolvidas na implementação e manutenção de práticas de sustentabilidade empresarial. Revista de Administração e Inovação, RAI, São Paulo, v. 11, n. 1, p. 345- 371, jul./set. 2014.

BRUM, T. T., MODOLO, R. C. E., MORAES, C. A. M. et al. 
NAWROCKA, D., \& PARKER, T. (2009). Finding the connection: environmental management systems and environmental performance. Journal of Cleaner Production, 17(6), 601-607.

NEVES, E. B.; ROZEMBERG, B. Estudo comparativo entre o sistema de gestão ambiental do exército brasileiro e a norma ISO 14001. Revista de Gestão Social e Ambiental, RGSA, São Paulo, v. 4, n. 1, p. 159-177, 2010.

OLIVEIRA, O. J.; PINHEIRO, R. M. S. Implantação de sistemas de gestão ambiental ISO 14001: uma contribuição da área de gestão de pessoas. Revista Gestão e Produção, São Carlos, v. 17, n. 1, p. 51-61, 2010.

SEIFFERT, M. ISO 14001 Sistemas de gestão ambiental: implantação objetiva e econômica. 3. ed. São Paulo: Atlas, 2007.

SILVA, A. R. A., FILHO (2008). Sistema de gestão ambiental como estratégia empresarial no ramo hoteleiro. Revista Produção Online, 8(3), 1-21.

TAUCHEN, J.; BRANDLI, L. L. Gestão ambiental em instituições de ensino superior: modelo para implantação em Campus universitário. Revista Gestão e Produção, São Carlos, v. 13, n. 3, p. 503-515, set./dez. 2006.

TO, W. M.; TANG, M. N. F. The adoption of ISO 14001 environmental management systems in Macao SAR, China Trend, motivations, and perceived benefits. Management of Environmental Quality, Bingley, v. 25, n. 2, p. 244-256, 2014.

YIN, R. K. Estudo de caso: planejamento e métodos. Porto Alegre: Bookman, 2005. Trad. Daniel Grassi.

ZUTSHI, A., \& SOHAL, A. S. (2004). Adoption and maintenance of environmental management systems: critical success factors. Management of Environmental Quality: An International Journal, 15(4), 399-419. 